\title{
SISTEM INFORMASI BERBASIS WEB DENGAN MODEL SUPPLY CHAIN MANAGEMENT (SCM) GUNA MENGATASI TARGET PENJUALAN YANG TIDAK TERCAPAI PADA PT. SETIA UTAMA DISTRINDO
}

\author{
Izur Rohman $^{1)}$, Bullion Dragon Andah ${ }^{2)}$ \\ ${ }^{1}$ Sistem Informasi, Fakultas Teknologi Informasi, Universitas Budi Luhur \\ 1,2Jl. Raya Ciledug, Petukangan Utara, Kebayoran Lama, Jakarta Selatan 12260 \\ E-mail : 1412520205@student.budiluhur.ac.id ${ }^{1)}$, bullion.dragon@budiluhur.ac.id ${ }^{2)}$
}

\begin{abstract}
Abstrak
Di era globalisasi dengan persaingan bisnis yang sangat ketat menuntut setiap perusahaan untuk menyusun suatu strategi bisnis agar bisa bersaing dengan kompetitor lainnya. Salah satu hal yang sangat penting adalah bagaimana membuat alur produksi maupun distribusi barang menjadi efektif dan efisien. Tentu itu akan menimbulkan kepuasan pelanggan dan membuat perusahaan semakin maju. PT Setia Utama Distrindo adalah perusahaan yang bergerak dibidang distribusi dan penjualan berbagai macam merk handphone. Terdapat kendala yang dialami oleh Perusahaan yaitu sales front yang tidak update terhadap jumlah stok barang sehingga sering terjadi kesalahan informasi stok kepada pelanggan, lamanya sistem retur barang menyebabkan komplain dari pelanggan, lamanya proses persetujuan pesanan yang mengharuskan pimpinan untuk menandatanganinya, juga terlambatnya pengiriman karena mobil yang sering mogok. Dari kendala tersebut penulis mencoba menganalisa dan memberikan solusi dengan menerapkan sistem Electronic Supply Chain Management (E-SCM). Penelitian ini dapat membantu mengembangkan sistem yang sudah ada dengan berbagai fitur usulan, berdasarkan pengumpulan data dan proses yang sudah berjalan di perusahaan, seperti adanya alert informasi service mobil secara berkala, persetujuan pimpinan dengan online, akses untuk sales front agar bisa melihat stok secara realtime dan alert informasi retur barang sehingga membuat proses retur menjadi efisien.
\end{abstract}

Kata kunci: electronic supply chain management, distribusi , E-SCM, efisien.

\section{PENDAHULUAN}

Di era globalisasi dengan persaingan bisnis yang ketat, hal ini sangat menuntut tiap perusahaan untuk menyusun strategi bisnis agar bisa bersaing dengan perusahaan lainnya. Dari berbagai persaingan bisnis tersebut dapat disimpulkan bahwa persaingan yang dilakukan oleh perusahaan adalah untuk mengimplementasikan proses produksi barang dan jasa yang efektif dan efisien untuk disalurkan kepada konsumen. Namun dalam kenyataanya perusahaan tidak mampu menjalankan semuanya dan memilih jalan yang cepat dan kemudahan dalam bersaing dengan kompetitor melalui Supply Chain.

Supply Chain Management (SCM) merupakan proses penting dimana arus pertukaran bahan dan keuangan juga koordinasi antar pihak-pihak yang terlibat di sepanjang rantai pasokan. Konsep pertukaran informasi dalam rantai pasokan ini dapat dikembangkan menjadi electronic Supply Chain Management (e-SCM). Dengan menggunakan teknologi informasi yang saat ini sering digunakan dalam kehidupan sehari-hari khususnya menggunakan teknologi berbasis internet website.

PT. Setia Utama Distrindo merupakan salah satu perusahaan di Jakarta yang bergerak dibidang distribusi dan penjualan berbagai macam merk handphone seperti Samsung, Xiaomi, Lenovo dan LG. Terdapat kendala yang dialami oleh perusahaan dalam meningkatkan penjualan seperti, sales front yang tidak update terhadap jumlah stok barang sehingga sering terjadi kesalahan informasi kepada pelanggan, lamanya sistem retur barang sehingga menimbulkan komplain dari pelanggan, juga lamanya proses persetujuan pesanan karena menunggu tanda tangan dari pimpinan dan mobil yang sering mogok sehingga menyebabkan terlambatnya proses pengiriman barang.

Dengan adanya kendala yang dialami PT. Setia Utama Distrindo, penulis mencoba menganalisa dan memberikan solusi sehingga diharapkan dapat membantu mengatasi kendala tersebut. Dalam upaya mendukung meningkatkan kinerja perusahaan dibutuhkan konsep pelayanan dengan Electronic Supply Chain Management yang dapat membantu proses distribusi barang lebih efektif dan efisien.

Masalah yang dialami oleh PT. Setia Utama Distrindo adalah sebagai berikut:

1. Persetujuan pesanan harus dengan tanda tangan dari pimpinan. Jika pimpinan tidak ada di tempat, ini akan memperlambat proses persetujuan. 
2. Lamanya proses retur barang, menimbulkan komplain dari pelanggan

3. Sales front tidak mengetahui stok barang secara realtime, sehingga sering terjadi salah informasi kepada pelanggan.

4. Kendaraan rusak karena jarang service, sehingga memperlambat proses pengiriman barang kepada pelanggan.

Tujuan dari penulisan penelitian ini adalah:

1. Mengidentifikasi proses bisnis serta menganalisa permasalahan yang berkaitan dengan proses pemesanan barang oleh pelanggan sampai proses pengiriman.

2. Merancang sistem informasi dengan pendekatan Supply Chain Management (SCM) berbasis web sebagai sarana untuk mendukung kegiatan ditribusi pada perusahaan. adalah:

Sedangkan manfaat penulisan penelitian ini

1. Memberikan alternatif solusi atas permasalahan yang dihadapi pada perusaahan.

2. Untuk membantu meningkatkan efisiensi dan efektifitas dengan menerapkan Supply Chain Management (SCM).

\section{STUDI LITERATUR}

\subsection{Definisi Supply Chain Management}

\section{(SCM)}

Menurut [1], Supply Chain Management didefinisikan sebagai berikut: "SCM adalah bagaimana caranya mengelola rantai pasokan yang efektif dan efisien”.

Tujuan SCM

Menurut [1], tujuan dari Supply Chain Management adalah:

"Mengendalikan dan mengembangkan organisasi melalui prinsip dan proses manajemen, yaitu menerapkan kegiatan planning (perencanaan), organizing (mengorganisasikan), directing (mengarahkan), executing (melaksanakan), dan controlling (mengendalikan). Sehingga dalam mengelola proses supply chain dapat menghasilkan produk yang efisien (murah) dan efektif (cepat dan tepat sasaran)".

Menurut [3], Supply Chain Management didefinisikan sebagai berikut:

"Perangkat pendekatan yang digunakan secara efisien untuk mengintegrasikan pemasok, produsen, serta gudang dengan toko-toko sehingga barang yang diproduksi dapat didistribusikan ke lokasi yang tepat, serta jangkauan system dengan biaya sesuai persyaratan tingkat pelayanan”. Dan menurut [7],

"Pengintegrasian sumber bisnis yang kompeten dalam penyaluran barang, mencakup perencanaan dan pengelolaan aktivitas pengadaan dan logistik serta informasi terkait mulai dari tempat bahan baku sampai tempat konsumsi, termasuk koordinasi dan kolaborasi dengan jaringan mitra usaha (pemasok, manufaktur, pergudangan, transportasi, distribusi, retail dan konsumen) untuk memenuhi kebutuhan pelanggan”.

\subsection{Konsep Dasar Supply Chain}

Menurut [1], konsep dasar supply chain dibagi menjadi 4 konsep:

a. Supply chain statis high dominasi.

Konsep ini dengan tingkat dominasi kuat oleh perusahaan inti yaitu perusahaan menjadi pusat rantai pasokan. Perusahaan menikmati tingginya pengaruh pada semua pihak yang terlibat dalam rantai membuat perusahaan inti mampu memilihmilih siapa yang layak menjadi supplier nya dan bisa juga menentukan hal-hal penting seperti persyaratan dan aturan main dalam supply chain. Contoh perusahaan McDonalds, IKEA, BOEING.

b. Supply chain dinamis high dominasi.

Konsep ini memiliki dominasi kuat yang dimiliki perusahaan inti yaitu perusahaan mampu memilih-milih siapa yang layak menjadi supplier nya dan pihak supplier harus mampu fleksibel mengikuti perubahan tipe produk dan cara produksinya serta sering terobosannya tidak terduga. Contoh perusahaan smartphone, komputer.

c. Supply chain statis low dominasi.

Konsep ini dengan tingkat dominasi rendah oleh perusahaan inti. Tipe ini perusahaan lebih mementingkan volume produksi dengan tipe produk yang hampir sama. Lebih mengutamakan efisiensi disegala bidang dan penggunaan utilisasi dan penuh kapasitas produksi. Tidak bias banyak memilih supplier kecuali patokan adu harga, dan tidak banyak perubahan proses dan tipe produknya. Contoh perusahaan tekstil, pabrik gula, pabrik sendok garpu. d. Supply chain dinamis low dominasi.

Konsep dengan tingkat dominasi rendah oleh perusahaan inti. Perusahaan ini sering berubah proses produksinya karena menawarkan banyak tipe produk yang baru sama sekali dan sering berbeda. Akhir-akhir ini muncul tren yang disebut industri kreatif, tipe usaha dalam industri ini sering menghasilkan produk inovatif sehingga patokan volume atau patokan kestabilan sangat dinamis. Contoh perusahaan event organizer (EO), production house $(\mathrm{PH})$, perusahaan travel wisata.

\subsection{Komponen Supply Chain}

Menurut [6], supply chain dapat dibagi menjadi tiga segmen utama:

a. Upstream supply chain segment

Supply chain dari sisi supplier dan organisasinya dimana aktivitas utamanya adalah 
purchasing dan pengiriman. Dimana sourcing atau pengadaan dari supplier external terjadi.

b. Internal supply chain segment

Segment yang meliputi keseluruhan proses yang dilakukan perusahaan dalam mentransformasi bahan baku yang dikirim oleh supplier menjadi barang jadi. Dimana proses manufacture, assembly, packaging terjadi.

c. Downstream supply chain segment

Segment proses ini meliputi distribusi dan pengiriman barang akhir atau barang jadi sampai ke konsumen tingkat akhir.

\subsection{Konsep Dasar Sistem}

Menurut [4], mengungkapkan sistem sebagai berikut: "Sistem adalah suatu kumpulan atau himpunan dari unsur, komponen, atau variabel yang terorganisasi, saling berinteraksi, saling bergantung satu sama lain dan terpadu”. Dan klasifikasi sistem menurut [8], dibagi menjadi beberapa sudut pandang yaitu: sistem abstrak,sistem fisik, sistem tertentu, sistem tidak tentu, sitem tertutup, sistem terbuka.

\subsection{Konsep Dasar Sistem Informasi}

Menurut [5],"Sistem informasi adalah kombinasi antara prosedur kerja, informasi, orang dan teknologi informasi yang diorganisasikan untuk mencapai tujuan dalam sebuah organisasi”.

\subsection{Use Case Diagram}

Menurut [2] use case diagram: "Use case diagram adalah visual yang menampilkan interaksi antara pengguna dan sistem informasi."

\section{METODE PENELITIAN}

\subsection{Identifikasi}

Untuk identifikasi masalah terdapat beberapa proses yang dilakukan seperti berikut:

1. Analisa proses dengan metode pengumpulan data secara observasi, wawancara dengan pihak terkait, mengumpukan dokumen serta menganalisanya dengan studi kepustakaan sesuai pembahasan.Dan membuat sturuktur organisasi pada gambar 1 .

2. Menganalisa proses bisnis berjalan dan mengidentifikasi masalah pada PT Setia Utama Distrindo dan menggambarkannya ke dalam activity diagram pada gambar 2-8.

3. Dari masalah yang ada kemudian digambarkan dengan fishbone diagram pada gambar 9. Dengan fishbone diagram akan terlihat sebab akibat terjadinya masalah yang terjadi.

4. Dari hasil identifikasi kebutuhan dibuatkan model datanya dengan use case diagram pada gambar 10-13 dan activity diagram.
5. Menggambarkan model sistem dengan Entity Relationship Diagram (ERD) pada gambar 14, lalu transformasi pada gambar 15, dan menjadi Logical Record Structure (LRS) pada gambar 16.

6. Membuat rancangan prototype yang meliputi rancangan layar sistem pada gambar 18-20, yang akan digunakan, rancangan masukan dan rancangan keluaran.

\subsection{Penyelesaian Masalah}

Konsep Supply Chain Management (SCM) tersebut dibutuhkan dalam membantu identifikasi permasalahan yang ada pada PT.Setia Utama Distrindo, dengan memaparkan masing-masing bagian dari setiap rantai proses distribusi pada perusahaan tersebut seperti gambar 15 , penambahan fitur input data mobil dan input service mobil agar meminimalisir terjadinya mobil mogok pada saat pengiriman barang. Dan pada gambar 21-23 menampilkan sequence diagram.

Pembuatan prototype rancangan sistem berbasis web sangat diperlukan untuk keperluan integrasi sistem dengan sistem lainnya. Dalam analisa dan perancangan sistem tersebut menggunakan konsep analisa dan perancangan berbasis objek. Dengan demikian penggunaan konsep Supply Chain Management (SCM) dan pembuatan rancangan sistem berbasis web ini dapat menjawab semua permasalahan yang ada dalam rantai distibusi barang pada PT. Setia Utama Distrindo.

\section{HASIL DAN PEMBAHASAN}

\subsection{Sejarah Organisasi perusahan}

PT Setia Utama Distrindo (SUD) adalah perusahaan swasta salah satu anak dari induk perusahaan PT Tiphone Mobile Indonesia, Tbk. Yang beralamat di Telesindo Tower, Jl. Gajah Mada no.27A Krukut, Taman Sari, Jakarta Barat. Didirikan pada tahun 2013 oleh bapak Hengky Setiawan, dan merupakan perusahaan distributor handphone berbagai merk, seperti LG, Samsung, Lenovo, Iphone dan Xiaomi.

\subsection{Struktur organisasi}

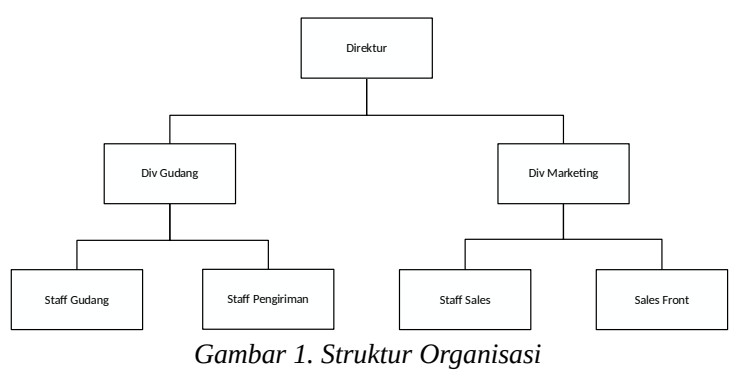




\subsection{Analisa Sistem Berjalan}

a. Analisa Proses Bisnis

1) Activity diagram entry data barang

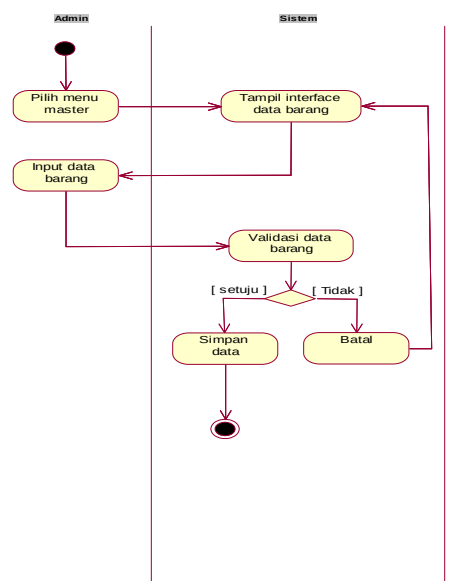

Gambar 2. Activity diagram entry data barang

2) Activity diagram entry data pelanggan

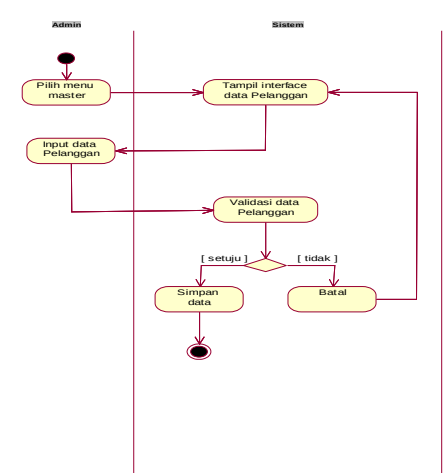

Gambar 3. Activity diagram entry data pelanggan

3) Activity diagram entry data pesanan

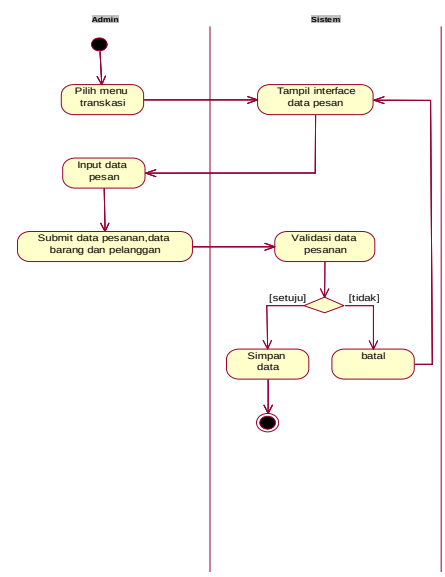

Gambar 4. Activity diagram entry data pesanan

4) Activity diagram cetak invoice

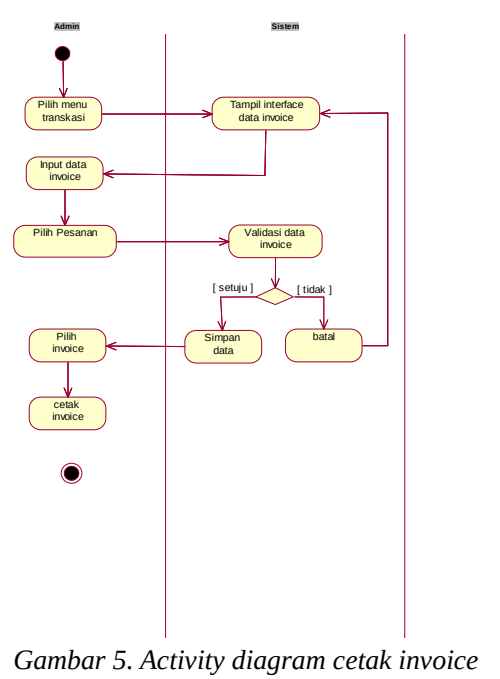

5) Activity diagram cetak surat jalan

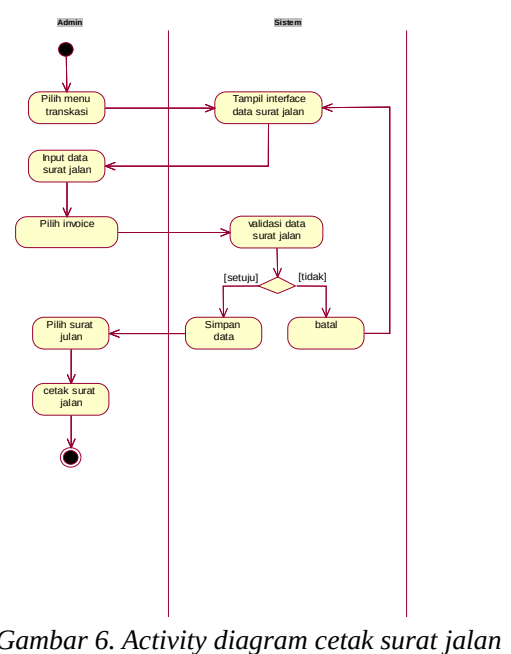

6) Activity diagram cetak laporan stok barang

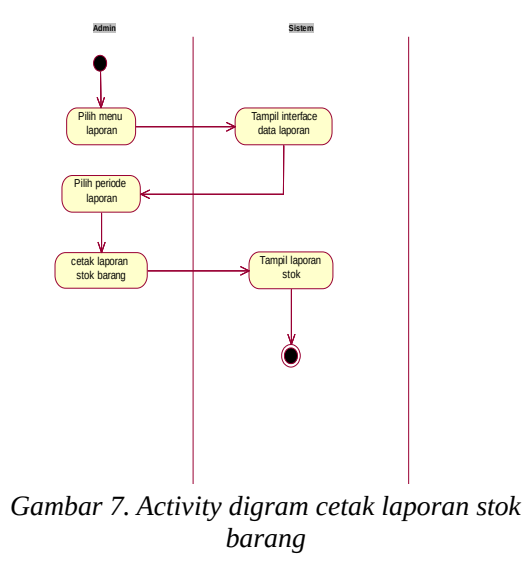


7) Activity diagram cetak laporan penjualan

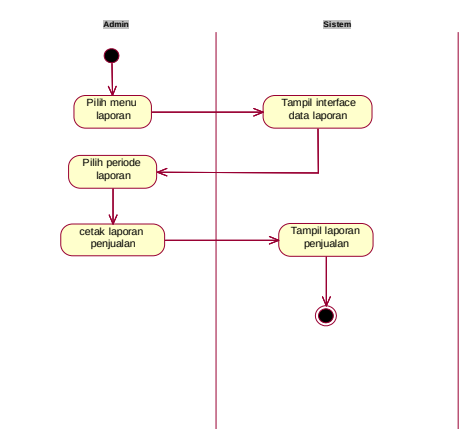

Gambar 8. Activity diagram cetak laporan penjualan

b. Analisa masalah

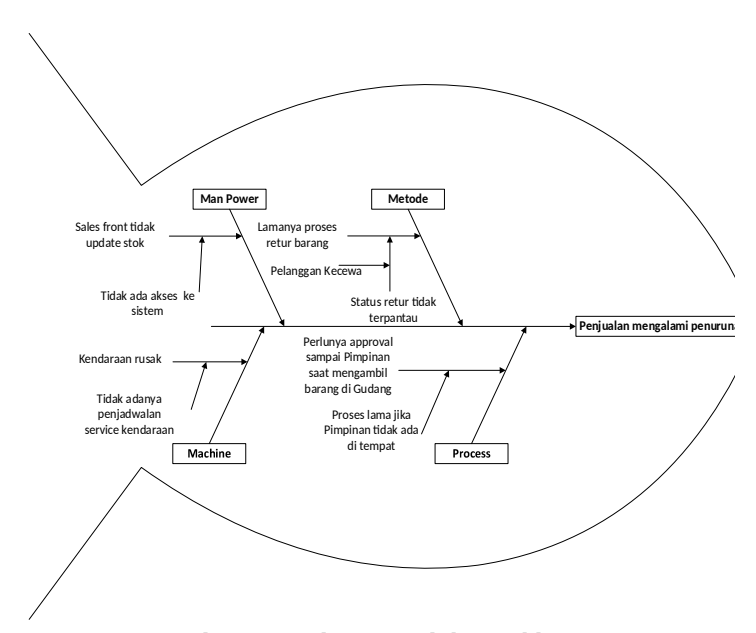

3) Use Case Diagram Transaksi

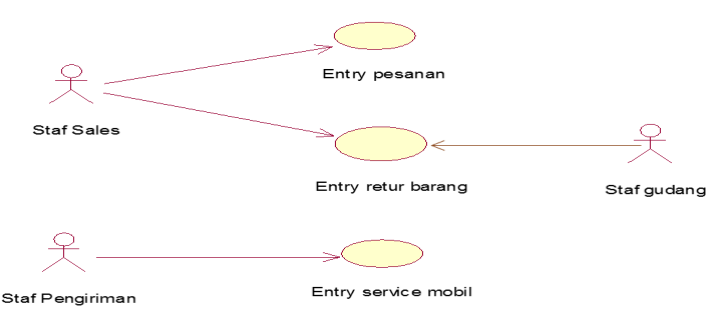

Gambar 12. Use Case Diagram Transaksi

4) Use Case Diagram Laporan

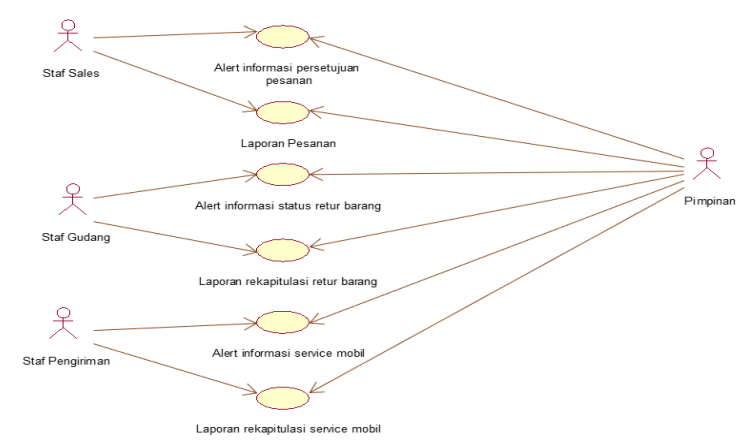

Gambar 13. Use Case Diagram Laporan

\subsection{Model Data}

a. Entity Relationship Diagram (ERD)

\subsection{Rancangan Sistem}

1) Use Case Diagram Login

$\therefore * *$

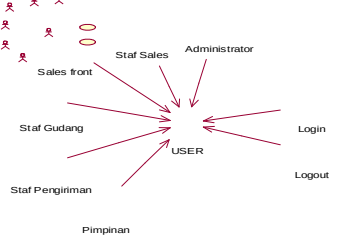

Gambar 10. Use Case Diagram Login

2) Use Case Diagram Master

Stat Pengiriman

Entry data mobil

Gambar 11. Use Case Diagram Master 
Gambar 14. EntityRelationship Diagram

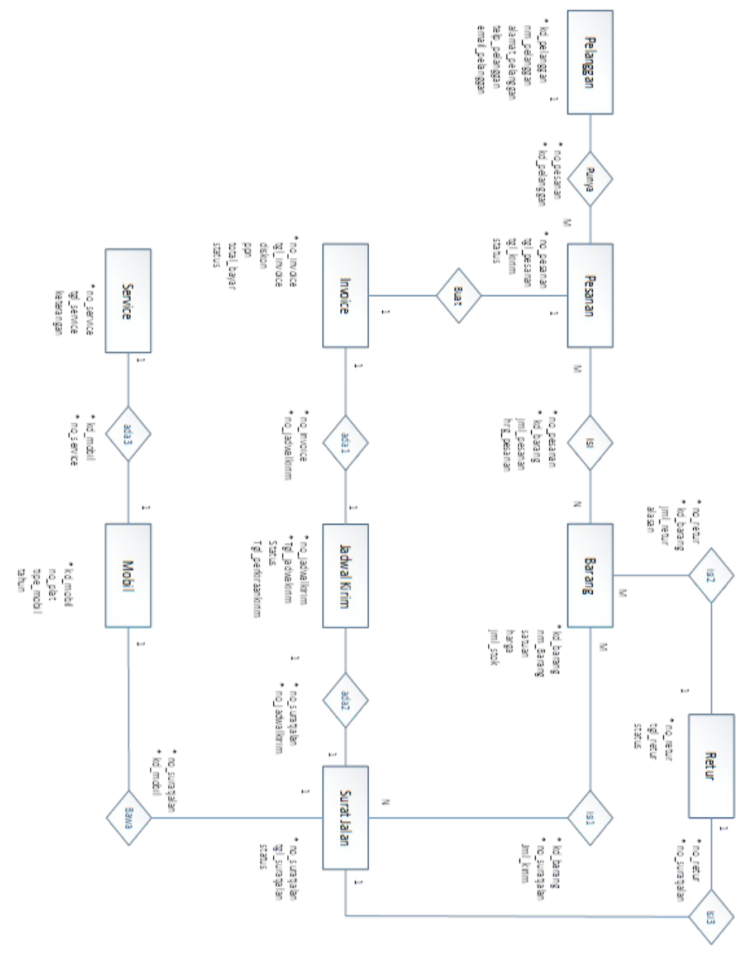

b. Transformasi ERD ke LRS

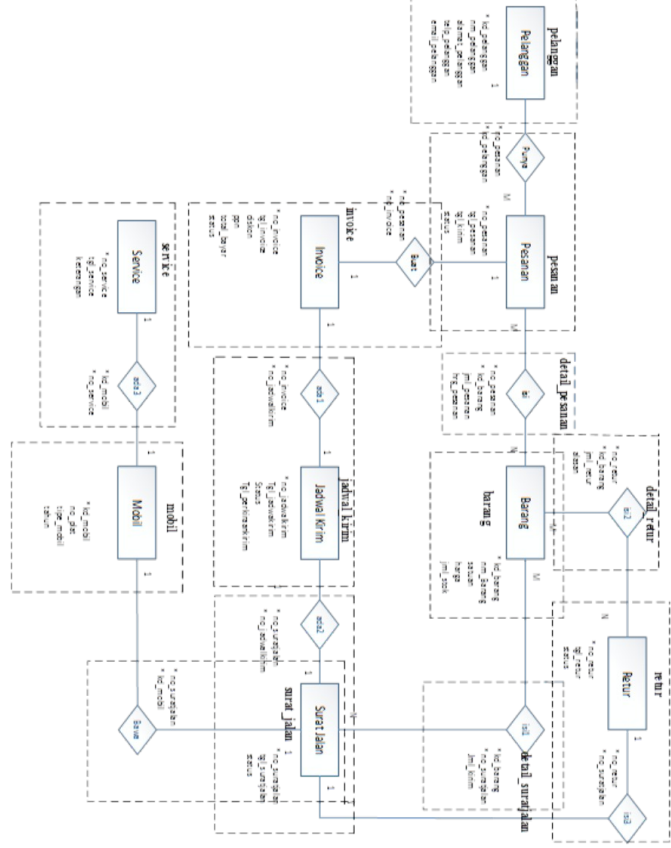

Gambar 15. Transfromasi ERD ke LRS 


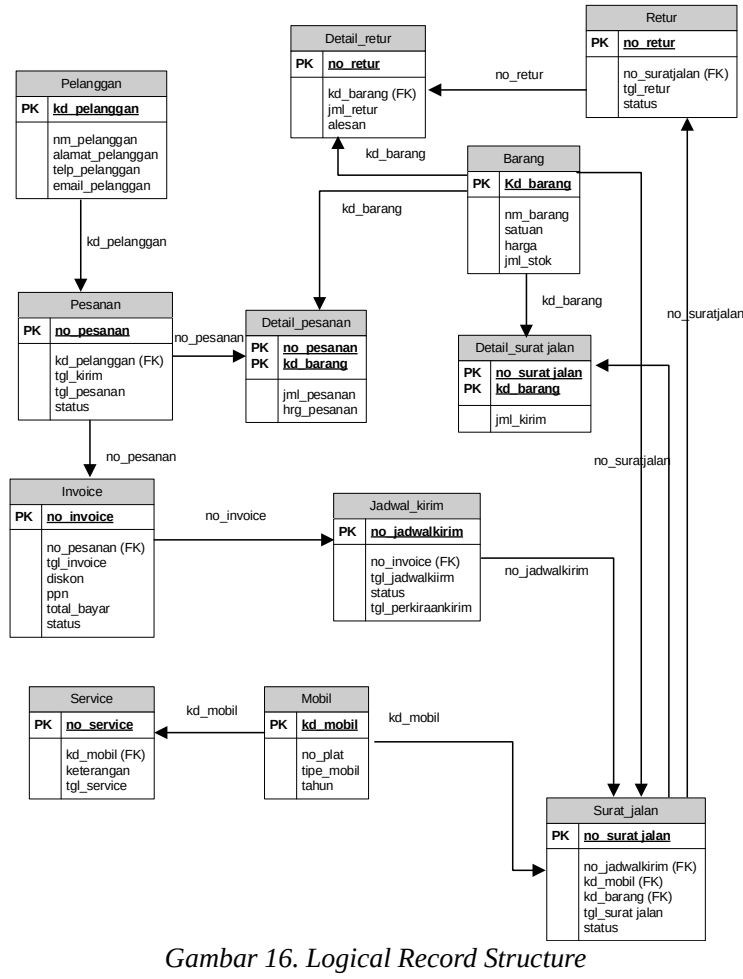

4.6. Struktur Menu

Struktur menu bisa dilihat pada gambar 17.
Gambar 16. Struktur Menu

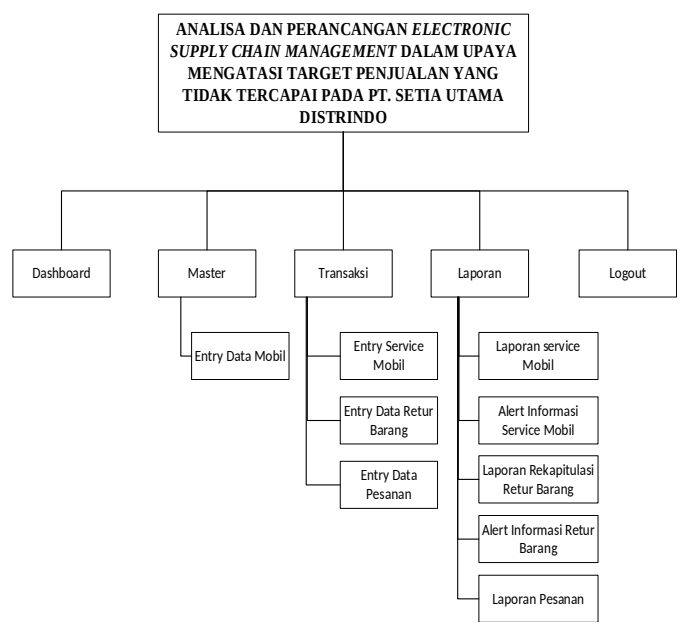

4.7. Rancangan Layar

a. Rancangan Layar Entry Pesanan

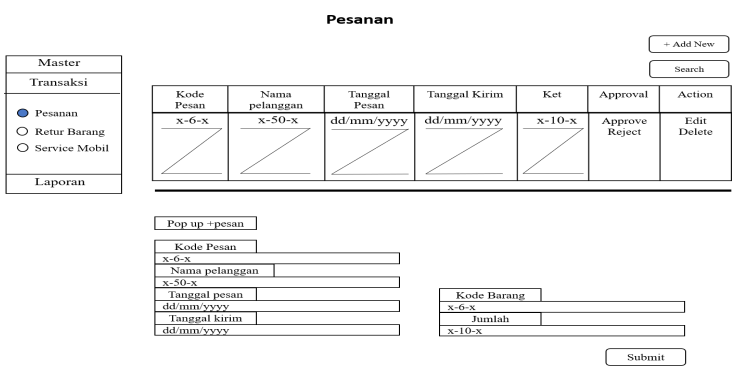

Gambar 17. Rancangan layar entry pesanan

b. Rancangan Layar Entry Service Mobil 

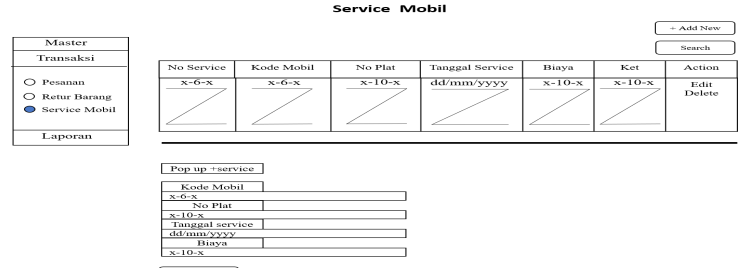

sutmit

Gambar 18. Rancangan layar entry service mobil

c. Rancangan Layar Laporan Service Mobil

Laporan Service Mobil
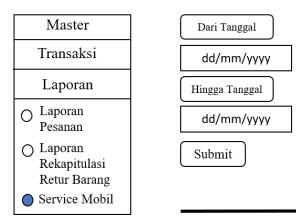

Gambar 19. Rancangan layar laporan service mobil

\subsection{Sequence}

a. Sequence Diagram Entry Data Mobil

$\therefore \mapsto \circ 0$

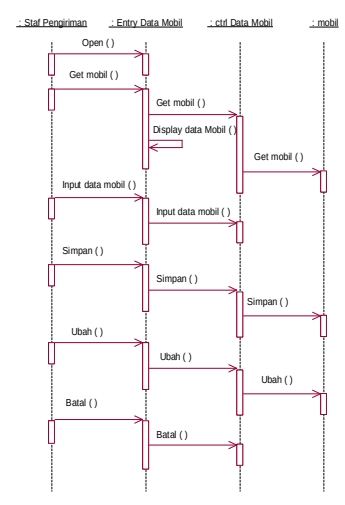

Gambar 20. Sequence entry data mobil

b. Sequence Diagram Entry Service Mobil
$* \circ \circ 0$

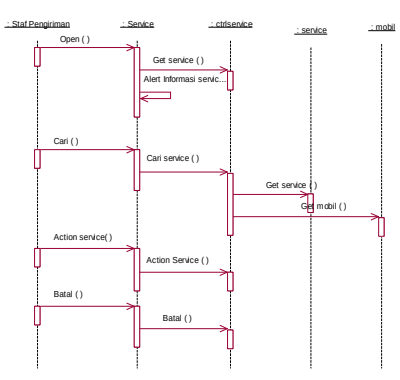

Gambar 21. Sequence Data Staff

c. Sequence Diagram Laporan Pesanan $\therefore \circ 0000$

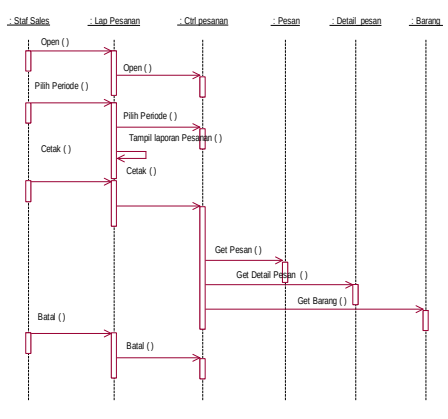

Gambar 22. Sequence Diagram laporan pesanan

\subsection{Analisa Masalah dan Solusi}

Tabel 1. Bobot Kriteria

\begin{tabular}{lll}
\hline No & Masalah & Solusi \\
\hline 1 & $\begin{array}{l}\text { Perlu adanya approval } \\
\text { (persetujuan) dari pimpinan untuk } \\
\text { mengeluarkan barang dari gudang, } \\
\text { sedangkan pimpinan jarang di } \\
\text { tempat, ini akan memperlambat } \\
\text { proses pengiriman }\end{array}$ & $\begin{array}{l}\text { Dibuatkan informasi } \\
\text { pesanan yang belum } \\
\text { disetujui }\end{array}$ \\
2 & $\begin{array}{l}\text { Lamanya proses retur barang, } \\
\text { sehingga menimbulkan komplain } \\
\text { dari pelanggan }\end{array}$ & $\begin{array}{l}\text { Dibuatkan informasi } \\
\text { reminder barang retur } \\
\text { untuk segera dikirim }\end{array}$ \\
& & $\begin{array}{l}\text { ulang, agar terus bisa } \\
\text { dipantau statusnya }\end{array}$ \\
3 & $\begin{array}{l}\text { Sales front tidak mengetahui stok } \\
\text { barang secara realtime, sehingga } \\
\text { sering terjadi salah informasi } \\
\text { kepada pelanggan. }\end{array}$ & $\begin{array}{l}\text { Dibuatkan akses untuk } \\
\text { sales front agar bisa } \\
\text { login ke sistem dan cek } \\
\text { stok barang secara }\end{array}$ \\
& $\begin{array}{l}\text { Kendaraan rusak karena jarang } \\
\text { Service }\end{array}$ & $\begin{array}{l}\text { Dibuatkan informasi } \\
\text { service } \text { kendaraan }\end{array}$ \\
\hline
\end{tabular}




\section{KESIMPULAN}

Berdasarkan penjelasan dan pemaparan yang telah dikemukakan pada penelitian ini, dapat ditarik kesimpulan bahwa:

1. Masalah lamanya proses approval atau persetujuan oleh pimpinan dapat diminimalisir dengan adanya informasi persetujuan secara online, dimana pimpinan dapat menyetujui suatu pesanan melalui akses web.

2. Masalah lamanya proses retur barang yang dapat diminimalisir dengan adanya alert informasi reminder barang retur untuk segera mengambil barang rusak dan mengirim ulang barang baru kepada pelanggan.

3. Dengan adanya akses kedalam sistem, Sales front dapat melihat secara real time jumlah stok barang, guna menghindari kesalahan informasi stok kepada pelanggan.

4. Dengan adanya alert informasi service kendaraan secara berkala, kendala pengiriman karena mobil rusak dapat diminimalisir, sehingga perawatan mobil lebih teratur.

Penulis berharap bahwa system yang telah dirancang untuk terus dikembangkan demi kemajuan organiasi, maka penulis memberi beberapa saran, yaitu:

1. Rancangan sistem aplikasi Supply Chain Management (SCM) berbasis web yang dibuat diharapkan dapat dikembangkan kembali untuk meningkatkan efisiensi dan kecepatan arus informasi antar bagian-bagian yang terkait.

2. Dibuatkan infrastruktur jaringan untuk mendukung sistem aplikasi Supply Chain Management (SCM) berbasis web.

3. Agar terlaksananya sistem ini dengan baik, diharapkan adanya proses pelatihan dan kerjasama antara bagian-bagian yang terlibat.

4. Kemudahan akses pada sistem berbasis web bisa dimana saja sangat menunjang untuk mobilitas seluruh penggunanya.

\section{DAFTAR PUSTAKA}

[1] Bambang Prihatmanto, "Supply Chain". Jakarta, 2018.

[2] G.B. Shelly and H. Rosenblatt," System Analysis and Design”,Boston, 2010.

[3] Manahan Tampubolon, "Manajemen Operasi Dan Rantai Pemasok”, Jakarta, 2014.

[4] Tata Sutabri, "Analisis Sistem Informasi". Yogyakarta, 2012.

[5] Taufiq Rohmat. "Sistem Informasi Manajemen" Yogyakarta, Graha Ilmu. 2013.

[6] Turban Efraim, and R. K. Rainer, ”Introduction To Information Systems", NewJersey, 2009.

[7] Willem Siahaya, "Sukses Supply Chain Management”, Bogor, 2013.
[8] Yakub, ”Pengantar Sistem Informasi”, Yogyakarta, Graha Ilmu, 2012. 